\title{
Ventricular ectopy
}

Sir,

The proceedings of the British Cardiac Society (Br Heart f 1979; 41 : 360-384) include one abstract in which 'ventricular ectopy' is the subject. It was particularly disappointing to see this in the British Heart fournal as I felt quite certain that 'ectopy' was an unfortunate neologism both coined in and confined to the United States of America. Our dictionaries, both medical and general, define 'ectopy' or 'ectopia' as something which is found in the wrong place-usually a congenital calamity (I do not know about the OED). This subject has been dealt with in detail elsewhere for both this and other vogue words. ${ }^{1}$ I hope that this single linguistic aberration is not the initial sign of transatlantic contagion. Many of us here draw comfort from the notion that whatever the local assaults on the English tongue its guardians in London remain on the job.

David H Spodick, University of Massachusetts

Medical School, and

Division of Cardiology,

St. Vincent Hospital,

Worcester, Mass, USA.

\section{Reference}

${ }^{1}$ Spodick DH. Vogue words-ectopic language. $\mathcal{f} A M A$ 1978; 240: 2439-40.

\section{Editorial note}

It is true that we stared suspiciously at ectopy for a few days before passing it. We had heard it used over the past few years by all ranks of cardiological societies in many countries and frankly thought it served a purpose. If the beats were ectopic, how were we to describe in a word the occurrence of frequent ectopic beats? Seeing it in print, however, we have second thoughts and we are disturbed by Dr Spodick's protest because we share his aversion to vogue words. Yet, if not ectopy, what? In the meantime, Dr Spodick and other well-wishers may be assured that we are committed to do our best to avoid offensive neologisms. 